\title{
Dismal use of legal safety net for mental health patients
}

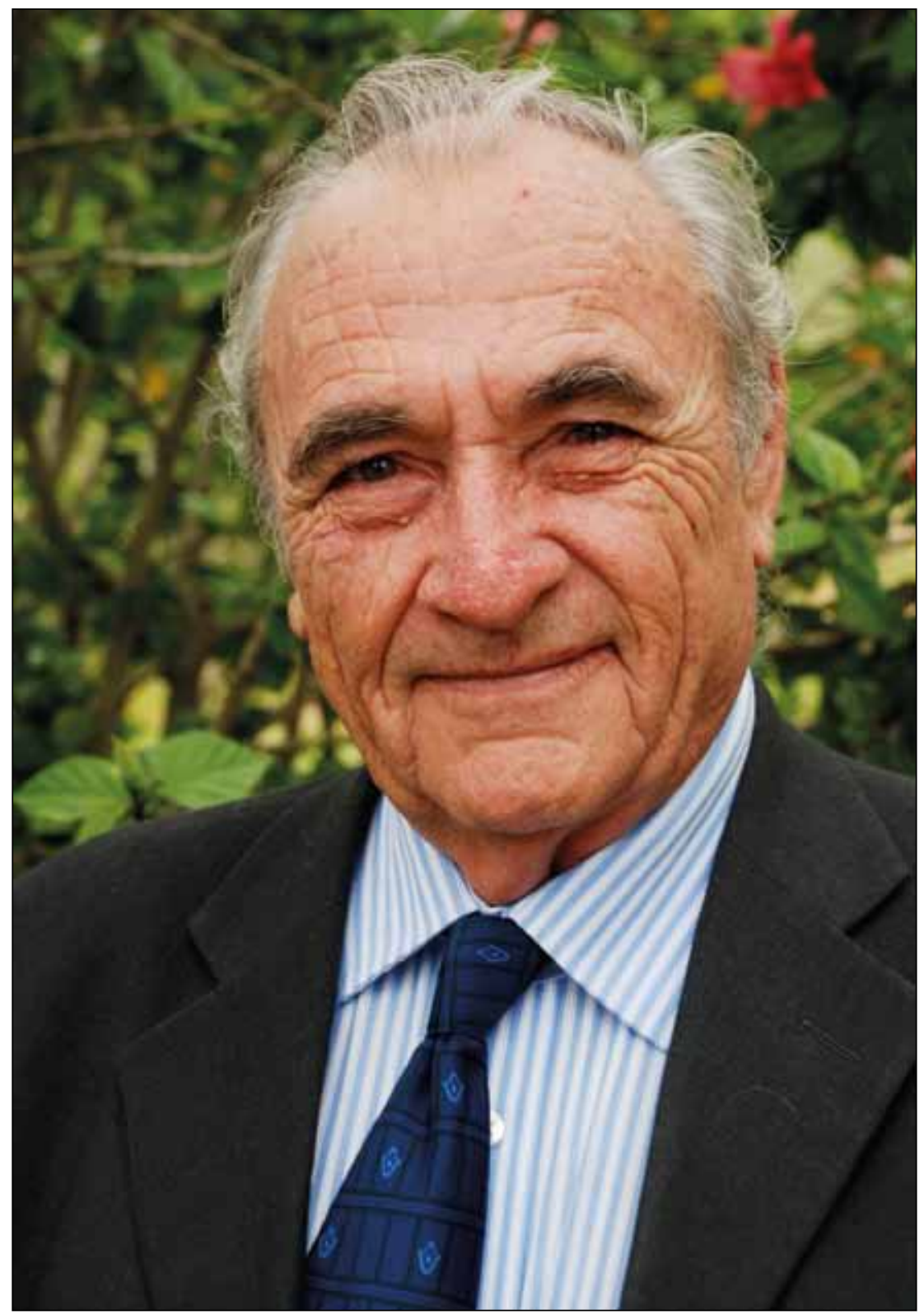

Dr Tom Sutcliffe.

It's been eight years since South Africa's ailing Mental Health Care Act was completely revised to better protect the human rights of patients with mental illnesses, thus revealing some horrific systemic and social abuses, but a dim ray of hope is that the safety net can be made to work.

One rare example is the Western Cape where, according to Dr Tom Sutcliffe, former provincial Director-General of terms of the revised Act, boards were set up incrementally across provinces from April 2005 onwards (Gauteng and the Free State have three each to cover their more numerous health districts, while many provinces have two).

\section{Dr Tuviah Zabow, Emeritus Professor of Psychiatry at the University of Cape Town (where he headed Forensic Psychiatry), said he found the general standard of implementation of the new Act 5 years after it was introduced 'pretty horrific'.}

Worryingly, most provinces have yet to meet the mandate and criteria of the new legislation. Dr Tuviah Zabow, Emeritus Professor of Psychiatry at the University of Cape Town (where he headed Forensic Psychiatry), said he found the general standard of implementation of the new Act 5 years after it was introduced 'pretty horrific'. He spoke out about this in the year he retired (2010) during a meeting in Gauteng aimed at 'changing policies and updating things' and attended by all the review boards. 'Unless things have really been jacked up since I left ... my impression is that the one down here (Western Cape) is functioning relatively well $\ldots$ and while I don't expect the tiny provinces to do fantastically well because of the lack of resources, they must all at least meet the legislative criteria.' His impressions are backed up by a review of the Applications for Involuntary Admissions made to the mental health review boards by health institutions in Gauteng in 2008. The authors of the paper $^{1}$ urge the provincial government to invest more funds to improve mental health human resources and infrastructure at all health establishments and, perhaps more importantly, recommend education of mental healthcare professionals and the public on a 'massive scale'. While they acknowledge 'significant strides' towards implementing procedures for involuntary admission and care, treatment and rehabilitation, these differed widely across institutions. In a subsequent letter to the South African Journal of Psychiatry ${ }^{2}$ in June 
last year, Dr Bernard Janse van Rensburg of Gauteng's Helen Joseph Hospital says the quality of the referral procedures and administrative record-keeping of his province's mental health review boards 'needs dramatic improvement,' adding that without these the human rights of mental healthcare users 'will continue to be compromised'. In KwaZulu-Natal, a July 2009 review of 49 regional and district hospitals designated by the Act to admit, observe and treat mental health care patients (for 72 hours before admission to a psychiatric hospital) found them to have inadequate staff and infrastructure, high administrative loads and a low level of contact with review boards. Over $80 \%$ had not been visited by a review board in the preceding 6 months. KwaZulu-Natal had $25 \%$ of the acute psychiatric beds and $25 \%$ of the psychiatrists required to comply with national norms. There was 'little evidence of government abiding by its public commitments to redress the inequities that characterise mental health services. ${ }^{3}$

Sutcliffe says that not only is the patient's right to dignity, treatment and proper care now legally protected, but so is their right to representation - plus the right to appeal admission to a mental health facility. 'More and more we see users [in his province at least] aware of the board and their rights. Everyone [is supposed to] get a rights card upon admission with our numbers on it. We've seen a quantum leap forward all round - providers now have a greater understanding of the Act via our training, documentation and the health department's courses for mental health providers, both nationally and provincially' His board receives between 6 and 10 appeals and complaints per week (up from 1 - 2 a month in 2005). The Act stipulates that a full report be put before the Board within 5 days of a complaint/appeal being registered. All cases involving involuntary care users (defined as someone suffering from a psychiatric illness or severe or profound intellectual disability that requires care, treatment and rehabilitation for his or her safety, or for the health and safety of others, and where such care and treatment are refused by the user), must be reviewed by the High Court. 'The judges are very diligent and conscientious - we get 3 - 4 queries a month from the Cape High Court,' Sutcliffe revealed.

\section{Dr Bernard Janse van Rensburg of Gauteng's Helen Joseph Hospital says the quality of the referral procedures and administrative record-keeping of his province's mental health review boards 'needs dramatic improvement', adding that without these the human rights of mental healthcare users 'will continue to be compromised'.}

The multiple mental health review boards are due to hold a summit this year (the last national review was in March 2009) and many provinces have adopted elements of the Western Cape's governance charter - but as Sutcliffe points out: 'Wherever you go demand exceeds capacity'. Asked about his province's overall provision of mental health services (mostly the 'poor cousin' in healthcare budgeting in spite of neuropsychiatric conditions being ranked third in their contribution to the overall burden of disease in South Africa - after HIV/AIDS and other infectious diseases), ${ }^{4,5}$ Sutcliffe said hospital staff were 'bit by bit not only getting to understand their role in mental healthcare but are being provided with the resources (such as high and low secure areas enabling the seclusion of patients needing sedation). In spite of a national shortage of mental healthcare nurses, there was now at least one such nurse at every district hospital in his province. Asked what he saw as the biggest challenge in mental health care, Sutcliffe said the existing high burden of disease was being aggravated by substance abuse, particularly 'tik', in his province. He put the percentage of cases being admitted to mental health facilities due to substance abuse 'upwards of $35 \%$ '. 'I suspect it's better in other provinces but what worries us is that tik has spread from the Cape Flats to people in small villages across the province - and so-called leafy suburban households are not spared the risk.'

Sutcliffe was recently awarded an ad eundem Fellowship in Psychiatry by the Colleges of Medicine of South Africa (the only one ever given) for his groundwork in setting up his highly replicable Mental Health Review Board. He is full of praise for the current Western Cape Premier Helen Zille's incentivised drug testing and wellness approach and believes passionately in the creation of sporting role models and sport/environmental awareness programmes for children. 'We can also put a lot more attention on the early diagnosis and treatment of postpartum depression and alcohol abuse among mothers through our antenatal clinics,' he added.

\section{Chris Bateman}

chrisb@hmpg.co.za

1. Moosa MYH, Jeenah FY. A review of the applications for involuntary admissions made to the Mental Health Review Boards by institutions in Gauteng in 2008. South African Journal of Psychiatry 2010;16(4):125-130.

2. Janse van Rensburg B. Applications to Mental Health Review Boards by institutions in Gauteng. South African Journal of Psychiatry 2011;17(2):64.

3. Burns JK. Mental health services funding and development in KwaZulu-Natal: A tale of inequity and neglect. S Afr Med J 2010;100(10):662-666

4. Bradshaw D, Norman R, Schneider M. A clarion call for action based on refined DALY estimates for South Africa. Editorial. S Afr Med J 2007:97:438 440

5. Nomed R, Bradish D, Scher M, Pietese D, Goew P. Reva R, Bradshaw D, Schneider M, Pieterse D, Groenewald P. Revised Burden of Disease Estimnates for the Comparative Risk Factor Assessment. South Africa 2000. Methodological Notes. Cape Town: Medical Research Council. http://www.mrc.ac.za/ bod/bod.htm (accessed 12 January 2012 


\section{A mental health review board in action}

A quick glance at some cases reviewed by the Western Cape review board shows just how the new constitutionally aligned legislation is beginning to impact - and exposes glaring weaknesses in the judicial and penal system.

An application for involuntary care on behalf of a drug user (the Mental Health Act categorises patients under 'voluntary care', 'assisted care' and 'involuntary care') came before the board for routine assessment. Its members picked up in the documentation that he was suffering from seemingly inexplicable 'bedsores'. They asked social workers at the relevant hospital for an explanation, given that he was fully ambulant, and set up interviews with the patient and his mother. What emerged was horrific abuse by the man's estranged stepfather who had tied him to a bare metal bed frame for a month, periodically beating him and denying him adequate food or access to a toilet. This was after the patient was briefly admitted to and discharged from a day hospital near his home, where he presented with psychotic symptoms. Police were summoned to the home after complaints of domestic violence, but not informed of the abuse - and did nothing further. The man's desperate family (his mother was too afraid to enforce a protection order she had against the stepfather who also abused her), contacted the Department of Social Development. Social workers referred the patient to another day hospital for 72 hours of observation, after which he was transferred to the district hospital for ongoing care, treatment and rehabilitation. Concerned mental healthcare practitioners there quizzed the social workers about the injuries, but the official report remains silent as to why more holistic remedial action was only taken once the review board became involved. Board interviews with all role players (except the stepfather, who was formally cautioned) resulted in the Health Department agreeing to monitor the patient's health on discharge and subsequent enforcement of the protection order. The victim, now an outpatient, has since complied with psychiatric treatment and suffered no

The man's desperate family (his mother was too afraid to enforce a protection order she had against the stepfather who also abused her), contacted the Department of Social Development. relapses, is attending care/support groups and has only occasionally suffered substance abuse relapses (he is reportedly 'motivated to manage this problem').

\section{Mother stigmatised}

A second case that was cited involved a female involuntary in-patient found to be 'delusional and grandiose with impaired insight and judgement', who was picked up at a major public transport terminal concourse in March last year with her two minor children. A month later she appealed her categorisation and voiced concern about the custody of her children after she was admitted to a tertiary hospital. The board found that her legal rights were being violated by a lawyer who, while ostensibly representing her, was acting for her ex-husband to obtain temporary custody of their children. It met with her and obtained an independent psychiatrist's evaluation and re-assessment which resulted in her appeal being upheld and her being designated more suitable for voluntary care, treatment and rehabilitation. The woman was also referred to Legal Aid for help with her legal challenges and continued to receive psychiatric care as a voluntary patient while getting social work help to resolve some of her 'immediate social problems'.

\section{The board found that her legal rights were being violated by} a lawyer who, while ostensibly representing her, was acting for her ex-husband to obtain temporary custody of their children.

\section{Ramifications of fetal alcohol syndrome?}

A third case was reported to the Western Cape review board by staffers at a school for children with learning disabilities which a 16-year-old serving a 5-year jail sentence for rape attended. They questioned the legal procedure adopted in the boy's conviction and sentencing, asserting that he must have been mentally impaired at the time of the offence and that the court had not taken account of this. (No enquiry into his criminal responsibility was ordered.)

The boy came from a poverty-stricken farm background where alcohol abuse was the norm; he had two siblings, also with learning disabilities, all suspected to be due to fetal alcohol syndrome. The board referred the case to the Legal Aid Board to file an application for leave to appeal the conviction and sentence and prompted Correctional Services to begin an application for parole (and to finally admit that his jail accommodation was 'inappropriate'). Correctional Services said it was incapable of dealing with a person with his special needs - but his domestic circumstances were also unsuitable. This left any magistrate asked to grant bail (pending the review) with a dilemma. The likelihood was that the teenager would remain in prison until the appeal because he was 'too high functioning' for admission to a psychiatric hospital.

The tertiary hospital's Child and Mental Health Services found that the boy was intellectually disabled to a significant degree, probably within the mild to moderate range' and unable to act on his appreciation of wrongfulness at the time of the alleged offence 'owing to intoxication and limited understanding of the situation at hand'. He was also 'less able than most' to assess the possible consequences of his behaviour. The board recommended intensive psychosocial rehabilitation, appropriate to his level of ability, with 'individualised social skills training' and a sexual offender rehabilitation programme suitable for his level of intellectual functioning. Should he be paroled, it should be under strict supervision, with a supervised job opportunity the ideal. Ongoing followup by the Intellectual Disability Services and Community Mental Health Services was 'appropriate and necessary'.

\section{The board recommended} that the Department of Correctional services consider the need for separate and dedicated facilities for prisoners of all ages who are intellectually disabled.

The board recommended that the Department of Correctional services consider the need for separate and dedicated facilities for prisoners of all ages who are intellectually disabled, 'both as a measure to ensure their greater physical safety and a means to provide appropriate and individualised psychosocial rehabilitation, thus reducing the chances of recidivism?.

\section{Chris Bateman}

chrisb@hmpg.co.za 